\title{
Serious Gaming Used as Management Intervention to Prevent Work-Related Stress and Raise Work-Engagement among Workers
}

\author{
Noortje Wiezer ${ }^{1}$, Maartje Bakhuys Roozeboom ${ }^{1}$, and Esther Oprins ${ }^{2}$ \\ ${ }^{1}$ TNO, Work \& Health, Hoofddorp, The Netherlands \\ ${ }^{2}$ TNO, Training and Performance Innovation, Soesterberg, The Netherlands \\ \{noortje.wiezer, maartje.bakhuysroozeboom\}@tno.nl, \\ esther.oprinsatno.nl
}

\begin{abstract}
Work-related stress is a large occupational risks in the Netherlands but interventions to reduce this risk are not implemented in organizations. The characteristics of a serious game make it a useful training tool for managers to raise awareness on their role in stimulating work engagement and managing work-related stress. In this research project a serious game for managers is developed and implemented and will be evaluated as an intervention to reduce work-related stress and raise work-engagement among employees. The evaluation will be done in a longitudinal case-control study, using a generic, standardized evaluation framework for validation of serious games. Focus of the evaluation will be on the direct effects of playing the game and on long-term effects, cf. transfer of training. In this paper the development of the game and the design for the evaluation study will be described.
\end{abstract}

Keywords: work-related stress intervention, management intervention, workengagement, serious gaming.

\section{Introduction}

Work related stress is one of the largest occupational risks in the Netherlands. Over $13 \%$ of the employees in the Netherlands report mental fatigue due to work, and this percentage is increasing (Koppes et.al 2010). Developments like the increase of restructuring, the growing amount of information an employee has to process, the individualization of society, increase the risk of work related stress even more. Work related stress is an important cause for mental health problems, absenteeism and early retirement. Research of the OECD showes that employees with 'mental health complains', are less productive, score higher on presenteeïsm, are more careless than employees without complains and therefor create risks for colleagues (OECD 2012). For all these reasons, costs of work related stress are high. In the Netherlands the costs of sick leave due to mental illness, partly caused by work related stress is estimated at 2,7 billion Euro (de Graaf et al, 2010). Nevertheless, interventions to 
reduce or prevent work related stress are not implemented in organizations. Results of an annual survey among employees in the Netherlands $(\mathrm{N}=22.742)$ show that $40 \%$ of the respondents indicate that measures to reduce work related stress are necessary but not sufficiently or not at all taken in their company (Koppes et. al 2010). Annual research among employers shows similar results. Although $49 \%$ of the employers indicate that work pressure (imbalance between job demands and job resources) is one of the major occupational health risks in their company, more than a quarter (26\%) does not take any measures to improve occupational health and safety, let alone measures to reduce work related stress (Oeij et. al 2008). The Netherlands are not an exception in Europe. Results of an EU-OSHA study (2012) on the ESENERdata show that although on average almost $40 \%$ of the companies indicate that stress is a major concern, only $24 \%$ has procedures in place to deal with work-related stress. In this same study factors are examined that make dealing with psychosocial risks difficult. Sensitivity of the issue and a lack of awareness are the most important reasons for management not to deal with psychosocial risks. Lack of training and experience and the culture within the establishment are other important reasons (EUOSHA, 2012). Houtman et.al (2012) looked at the reasons for Dutch companies not to take measures, even if they are scientifically proven to be effective. The results of their research is similar to the results of the ESENER study. Company (or sector) culture hinders interventions on this sensitive topic. Work related stress is not a topic that is easily discussed in most companies. The unawareness of the risks and lack of insight in the consequences of the risks are barriers to act on reducing these risks. Lack of awareness of the problem and the consequences hinders commitment of management to deal with psychosocial risks. Not only does this affect the willingness of management to take measures, it also affects the success of interventions. For interventions on psychosocial risks to be successful management commitment is very important. Individual managers indicate that they 'don't know how to recognize stress signals, and also have little confidence in the impact of their own actions on the work related stress of their employees' (Wiezer et. Al. 2012). Houtman et. al. (2012) also looked at reasons for companies to do take measure. Past positive experiences with interventions, own experiences or experiences from colleagues, increase the willingness for managers to work on decreasing risks.

The intervention we aim at therefore has three goals. First, it should create a sense of urgency among managers to deal with psychosocial risks. Second, the intervention should increase the self-efficacy of managers to deal with these issues. Third, the intervention should contribute to an actual change in the behavior of managers to deal with these issues.

Serious Gaming: In this project we are looking for an intervention that eventually will change managers' behavior concerning psychosocial risks. In often used behavior changes models several key elements are defined that increase the intention of a person to change its behavior (see for example the I-change model, Brug et al 2007). Outcome expectations' (what will be the benefits or the effects of the preferred behavior), 'risk perception' (what will happen if I don't change my behavior), feedback (am I doing alright? What can I do to improve), task-efficacy' (the 
confidence in your ability to show the preferred behavior), and performance skills (needed to show the preferred behavior) are among the important ones. A serious game could be an effective and appropriate mean to reach behavioral change.

Serious games are often defined as games that serve other goals than entertainment (Harteveld 2011, 2012). A well-developed serious game has a number of features. For a serious game to be effective fidelity is important. The virtual world should be as authentic, realistic and convincing as possible, although it is sometimes necessary to simplify reality in order for the player to be able to understand the game rules. This not only applies to the visible representation of the game world, but also to the scenario's and the behavior of the characters in the game. According to Graesser, Chipman, Leeming and Bid Bach, (in Ritter Field, Cody \& Vorderer, 2009) a welldeveloped serious game matches the interests and perceptions of the player, and provides the player with the opportunity to actively play the game and try and experiment with different approaches which lead to alternative game situations. The difficulty of the game should be well balanced. The game is challenging enough to keep players motivated to play and improve the score. The players are able to experience success in their game. Success experiences creates self-efficacy (Lepper and Woolverton, 2002). In a well-developed game there will be feedback on actions. This affects the commitment, effort and self-efficacy of the player (e.g. Jackson \& Greasser, 2007). A storyline in the game makes the gaming experience more memorable. Finally, a good serious game is fun to play (Vorderer, Klimmt \& Ritterfeld, 2004). When a game is fun, a player is motivated to continue and replay the game. A serious game containing these features will offer players the opportunity to experiment in a safe environment and to learn by experiencing. Serious games have the advantage that effects of interventions can be scaled, not only short term but also medium and long term effects can be shown and experienced during the game. This will provide outcome expectations but will also increase the risk perception. Players can try different styles, behavior or interventions without fearing negative consequences. In this sense, a serious game on psychosocial risks looks like a promising tool. The topic is complex and outcome expectations and risk perception are not easily met. A game will help players to increase the awareness on psychosocial risks, to understand their role in managing these risks and to increase their self-efficacy in doing so. Psychosocial risks is also a very sensitive topic, sharing experiences on this topic is not easily done by managers. A game will provide a fun and safe way of dealing with this topic.

There has been research done on the effectiveness of serious games (see the recent reviews by Sitzmann (2011) and Connoly, Boyle, MacArthur, Hainey \& Boyle (2012). Computer games and serious games are linked to perceptual, cognitive, affective, motivational and behavioral outcomes. Most evidence is found on the effects of serious games on learning. By playing a (well-developed) game, people experience flow, which increases the motivation to keep on playing and thus practicing and learning. Spending time on learning and practicing also increases the self-efficacy, which in turn help reaching the learning objectives of the game (Sitzmann, 2011). In this paper we describe the development of a serious game for psychosocial risk management and the research design for validating this game. 


\section{Work Related Stress and Engagement}

Fidelity is important for a game to be effective. It is therefore important to base the development of the game on an evidenced based theoretical model. The Engagement game is a serious game, that can be used as a training tool for managers to raise awareness on their role in stimulating work engagement and managing work-related stress. Work-related stress and work engagement are the two most important (learning) objectives in this game. For the Engagement game, described in this paper we combined the theoretical models of work related stress and work engagement.

A lot of research has been done into the topic of work-related stress. A number of models are developed and several definitions exist for the concept. For the Engagement game we used a definition that is widely used in research, but can also easily be translated into game rules. Work-related stress is defined as: a state, which is accompanied by physical, psychological or social complaints (sometimes expressed in behavior) that is caused by an imbalance between requirements and expectations at work and the ability of a person to meet these requirements and expectations. An individual is well adapted to cope with short term exposure to stress, but has great difficulty coping with prolonged exposure to intensive stress.

Work engagement fits into the tradition of positive psychology. In this tradition the focus is not on negative outcomes or states but on the positive ones (Seligman \& Csikszentmihalyi, 2000). What increases mental health and well-being (even for people that are already relatively healthy and happy), is the central question. For work-engagement we used the definition developed by Schaufeli and Bakker (2001): Work engagement is a positive work-related state of fulfillment that is characterized by vigor, dedication and absorption.

Almost all recent models on work related stress define stressors: factors that can evoke stress reactions (for example high job demands), and moderators: factors that can reduce, or increase if they are absent, the effect of stressors (for example organizational of personal resources like autonomy, social support, learning and development opportunities). In all models the balance between stressors and resources is important. If there is a good balance between stressors and resources, work related stress will not occur. If there are not enough resources to meet the stressors, than work related stress will occur. A proper balance between job demands and resources, which are motivational in nature, may also lead to positive outcomes such as work engagement. The more recent Job Demands Control model (Bakker, Schaufeli \& Demerouti, 1999 and Bakker \& Demerouti, 2007) complement the work related stress models and additionally focus on the positive aspects of well-being (engagement). The model used in the Engagementgame is based on the Job Demands Control Model.

Figure 1 shows the model used in the game. An imbalance between job demands and organizational and personal resources increases work related stress, which in turn has a negative effect on for example health and productivity of employees. Organizational and personal resources increase work engagement. This is even more the case if organizational and personal resources are combined with challenging job demands. Work engagement in turn has a positive effect on organizational outcomes such as health and productivity. 


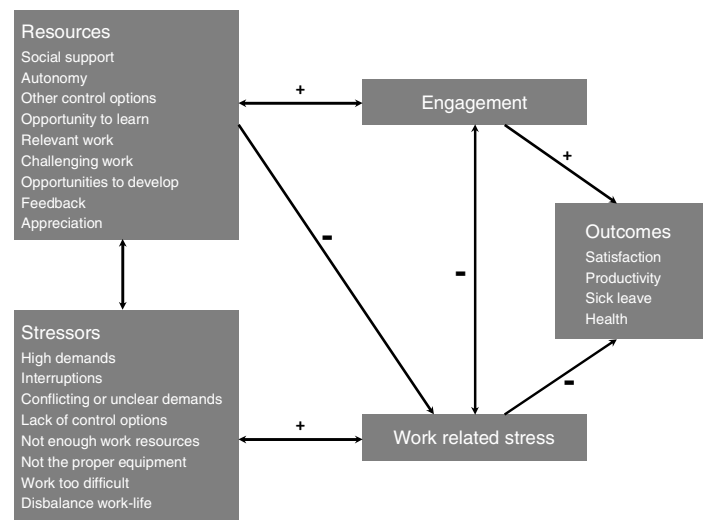

Fig. 1. The theoretical model used in the Engagement game

\section{The Development of the Engagement Game}

The development of the Engagement game was a collaboration of four parties: A large health and safety consultancy firm, a large bank, a game developer and a research institute. All parties had a different role. The scientific background for the game was provided by the research institute. Together with the game developer they translated the theoretical models into game rules and scenarios. The game developer build the game. The participants from the consultancy firm and the bank provided the 'reality check', from their experience with day to day practices in companies and helped develop the scenarios. The bank incorporated the Engagement game in the leadership training program for their own managers and the consultancy firm developed a training for leadership and engagement of which the Engagement game is an important element.

The project to develop the Engagement game was divided into three work packages. In the first package the theoretical model was developed, which is described in the previous paragraph. A literature review into empirical evidence for the described relationships was conducted. At the time of this review not many longitudinal studies were published on the (relatively new) topic of work engagement. Where empirical evidence was not found, relative strength of relations were estimated by experts in the field of work-related stress and work engagement, that were consulted. In the second work package the theoretical model is formalized and translated into game rules and scenarios. For this step we first had to determine what the 'learning goals' were we wanted to reach with our game. What is the message we want to bring across? For this message to be clear, and for the player to be able to understand the message it was necessary to simplify the model into a working model that contains only the most essential and important relationships. It took several meetings with experts in the field to develop this working model. In the third package the game was build. For building the game an 'agile approach' was used, the theoretical model was translated into game rules and game specifications and functionalities in little steps. After each step there was a feedback round and the last 
steps contained feedback from end users as well. We were constantly testing whether the scenarios and the game rules were authentic, realistic and convincing, whether different learning styles were used (visual, active, reflective, experimental), whether different playing styles could be used (more pragmatic, more theoretical), and whether the game was challenging enough so players would stay in a flow while playing it.

For the Engagement game we used the story of the manager of a Mexican restaurant. We chose for this metaphor because we would never succeed in building an exact copy of the work situation and work processes of the player (for instance a manager in a bank). If we suggested an exact copy of the work of the player, every deviation of that would disturb the flow of the player. We chose for a restaurant because this is a situation most players can relate to. As player you are the manager of this restaurant and you are assigned to increase the financial results. You have to manage six employees. These employees have tasks with job demands and they have resources, competences and ambitions. The balance between their job demands and their resources influences their work engagement and stress level. The work engagement and stress level of the employees in the restaurant influences the quality of their work and that influences the number of customers and thus the returns of the restaurant. Interventions of the manager (the player) changes the job demands or the resources and have an impact on the engagement and stress of the employees. To gather information you can talk to your employees (pull) and sometimes they come to you for a talk (push). Besides that they 'send tweets' to comment on your interventions (feedback). Customers also tweet, on their experiences in your restaurant. While you try to manage your restaurant all kind of events take place on which you have to react. And of course, measures taken to react on events also influence the work engagement and work related stress of your employees. We developed two scenario's, the second being more challenging than the first. Both scenarios can be played in twenty minutes and at the end feedback is provided on the reasons you did or did not reach the targets. The game is usually played in couples to stimulate discussion on the decisions, and as part of a training. After playing the game the results of all couples are discussed in the group. If the game is played 'standalone' (not as part of a training) a reflection form is added to stimulate the player to translate the game-experience into their own day to day practice.

\section{Evaluation of the Engagement Game}

Besides the development of the game, the evaluation of the effectiveness of the game is part of the project as well (fourth work package). The central research question of this evaluation study is 'is this serious game an effective intervention to decrease work related stress and increase work engagement in companies?' The Engagement game is effective if managers are better able to reduce work related stress and increase work engagement of their own employees after playing the Engagement game as part of a training. The effect of the Engagement game will therefore be examined on two levels: the level of the manager (the player) and the level of the 
employees of the manager. We are not only interested in the effects of the game itself, but also in the process: which elements influence the effectiveness of the Engagement game.

For the evaluation the following research questions will be answered:

1. Did the manager learn from playing the game?

- Is he better able to recognize determinants of work related stress and work engagement?

- Has his sense of urgency related to work related stress and work engagement increased?

- Did the intervention (playing the game as part of a training) change the behavior of the manager? (long term transfer of training)

2. Did this intervention reduces work related stress and increased work involvement among employees?

- Did the participation of the manager in the training program with the Engagement game increase the amount of resources for employees and/or decrease the amount of stressors?

- Did the participation of the manager in the training program with Engagement game reduce work related stress and increase work engagement among the employees of the manager?

- Did the participation of the manager in the training program with Engagement game lead to better organizational outcomes (reduced sick leave, better productivity)?

3. What are the success and fail factors for the effectiveness of Engagement game and why are these factors important?

- Factors that relate to the game design and learning experience (gaming mechanisms)

- Factors that relate to the implementation of the game and the training (process)

The evaluation will be done in a longitudinal case-control study, using a generic, standardized evaluation framework for validation of serious games developed by TNO and applied for other games (Oprins 2011). This evaluation framework consists of indicators, methods and instruments (questionnaires, checklists, data logging methods) with which the effectiveness of a serious game can be evaluated. The framework consists of more generic process measure aimed at learning and more domain specific outcome measures (specific content or specific competencies, in case of this study: understanding of stress and engagement theory). These measures can show a short term effect (right after playing the game) or a long term effect (transfer of training). The clustering of the case-control study is on the level of the workgroups. Two groups will be distinguished: an intervention group and a control group. The managers of the intervention group will receive a training with the Engagement game, the managers of the control group will receive a regular training without a serious 
game. To be able to show an effect on our primary outcome measure (work engagement of the employees), the number of managers we need in our research is 94. In addition, we need ten employees of each participating manager to be part of this research as well. For the effect and process evaluation a questionnaire will be filled out by managers and employees of both groups at three moments in time: before the intervention, right after the intervention and four months after the intervention. Semi structured interviews will be held with the managers of the intervention group. Multilevel analyses will be conducted on the data to determine if changes in the outcome measure differ for the intervention group and the control group.

In preparation of the evaluation study we organized a number of workshops for managers, in which the game is played. The first results of these workshops are described in the next paragraph.

\section{$5 \quad$ First Results}

The first results of the workshops are promising. Managers evaluated the game positively. There was a lot of laughter during the workshops. The fun factor was mentioned as one of the positive aspects of the game. This motivated the managers to play the game. They recognized the situations in the game and thought the speed of the game was good. The engagement of managers to the game was high. There was also a lot of discussion during the game and after the game, when results of the groups were presented. The discussion with colleagues was also one of the aspects that managers evaluated positively. Managers discussed interventions to decrease work related stress and increase engagement in their own work situation using examples and characters from the game. They were able to make the translation from the game world to their actual work situation. The game and the game story gave them 'words and examples' to talk about their own experiences. They indicated that after playing the game they had more understanding of the theory of work related stress and work engagement. They also experienced the role a manager could have in managing these risks. For some managers it was an eye-opener to see the effect of work engagement on the results of the restaurant.

Most players indicated that they would have liked to have more opportunities to intervene in the game. In the game players can choose between a limited number of 'standard' interventions (and this number increases if information is gathered by 'talking' to employees). Managers would have liked to be able to formulate their own interventions. They would also have liked to be able to have a 'real' conversation with the characters in the game, instead of just being able to select standard questions or remarks. To be able to experiment with more styles and types of behavior would have increased the perception of the influence a player has on the outcomes of the game.

\section{Discussion and Conclusion}

Work related stress is an important occupational risk in the Netherlands, and it is not dealt with enough by management in companies. This can be explained by 
unawareness of the risks and consequences, and lack of insight in the possible interventions and self- efficacy. Culture in companies often hinders to talk about this sensitive topic. The first results of our project suggest that playing the Engagement game increases the insight in the topic and provides a 'safe environment' to experiment with this sensitive topic. These findings are supported by research into the development of serious games (Graesser, Chipman, Leeming and Bid Bach, (in Ritter Field, Cody \& Vorderer, 2009).

The first experiences also show that although the game is important, the training in which the game is imbedded (the big game) is also very important. The link from experience (in the game) to understanding can only be made when there is a welldeveloped translation phase after playing the game. The effect of the game will also depend on the quality of the training in which the game is imbedded. This finding is supported by studies into the effectiveness of serious games as a tool for learning and training (see for example Sitzmann, 2011).

Our ambition is to show the effect of the Engagement game on the knowledge, competences and awareness of the players, on their self- efficacy to deal with topic and also on their behavior related to this topic. The hypothesis in this research is that the changed behavior of the manager will change the resources and stressors of the employees and thus change their levels of stress and engagement. This will affect the outcomes of the organization. Resources and stressors of employees can also be affected by other determinants than the behavior of the manager and that is even more the case for outcomes of the organization. Although the intervention group and the control group will be matched carefully, this could influence the results of this study.

There is a need for effective interventions, not only to manage psychosocial risks, but to manage all occupational safety and health risks. And not only is there a need for effective interventions, company management should also be convinced to work on these risks. If the Engagement game proves to be effective in increasing a players' awareness and sense of urgency to deal with risks, in changing their self- efficacy in dealing with the risks and in changing their behavior, this might be an indication that serious gaming is a promising new way of dealing with health and safety risks in general.

\section{References}

1. Bakker, A.B., Demerouti, E.: The job-demands resources model: state of the art. Journal of Managerial Psychology 22, 309-328 (2007)

2. Bakker, A.B., Schaufeli, W.B., Demerouti, E.: Werkstressoren, energiebronnen en burnout: het WEB model. In: Winnubst, J., Schuur, F., Dam, J. (eds.) Praktijkboek Gezond Werken, vol. II(3.2), pp. 1-19. Elsevier, Maarssen (1999)

3. Brug, J., van Assema, P., Lechner, L.: Gezondheidsvoorlichting en Gedragsverandering. van Gorcum, Assen (2007)

4. Connoly, T.M., Boyle, E.A., MacArthur, E., Hainey, T., Boyle, J.M.: A systematic literature review of empirical evidence on computer games and serious games. Computers \& Education 59, 661-686 (2012) 
5. European Agency for Health and Safety at Work. EU-OSHA, European Agency for Safety and Health at Work, Drivers and barriers for psychosocial risk management: an analysis of the findings of the European Survey of Enterprises on New and Emerging Risks (ESENER), Office for Official Publications of the European Communities, Luxembourg (2012)

6. de Graaf, R., ten Have, M., van Dorsselear, S.: De psychische gezondheid van de Nederlandse Bevolking [The Mental Health of the Dutch population]. Trimbos-Instituut, Utrecht (2010)

7. Graesser, A., Chipman, P., Leeming, F., Biedenback, S.: Deep Learning and Emotion in Serious Games. In: Ritterfeld, U., Cody, M., Vorderer, P. (eds.) Serious Games: Mechanisms and Effects, pp. 83-102. Routledge, New York (2009)

8. Harteveld, C.: Triadic game design: Balancing reality, meaning and play. Springer, London (2011)

9. Harteveld, C.: Making sense of Virtual Risks: a Quasi-Experimental Investigation into Game-Based Training. IOS Press, Amsterdam (2012)

10. Houtman, I., Kok, L., Klauw, M., van, d.L.M., Janssen, Y., Ginkel, W.: van.: Waarom werkgevers bewezen effectieve maatregelen wel of niet nemen [Why employers do or do not take proven effective measures]. TNO, Hoofddorp (2012)

11. Jackson, G.T., Greasser, A.C.: Content matters: An investigation of feedback categories within an ITS. In: Lucking, R., Koedinger, K., Greer, J. (eds.) Artificial Intelligence in Educattion: Building Technology Rich Learning Context That Work, pp. 127-134. IOS Press, Amsterdam (2007)

12. Koppes, L.L.J., de Vroome, E.M.M., van den Bossche, S.N.J.: The Netherlands Working Conditions Cohort Study. TNO, Hoofddorp (2010)

13. Lepper, M.R., Woolverton, M.: The wisdom of practice: Lessons learned from the study of highly effective tutors. In: Aronson, J. (ed.) Improving Academic Achievement: Contributions of Social Psychologie, pp. 133-156. Academic Press, Orlando (2002)

14. OECD, Sick on the job? Myths and Realities about Mental Health and Work. Mental Health at Work. OECD Publishing (2012)

15. Oeij, P.R.A., de Vroome, E.M.M., Sanders, J.M.A.F., van den Bossche, S.N.J.: Werkgevers Enquête Arbeid [ Empoyers Working Conditions Survey]. TNO, Hoofddorp (2008)

16. Oprins, E.: Evaluatieraamwerk voor het evalueren van Serious Games, onderzoeksvoorstel (researchproposal). TNO, Soesterberg (2011)

17. Schaufeli, W.B., Bakker, A.B.: Job demands, job resources, and their relationship with burnout and engagement: a multi-sample study. Journal of Organizational Behavior 25, 293-315 (2004)

18. Seligman, M.E.P., Csikszentmihalyi, M.: Positive psychology: An introduction. American Psychologist 55, 5-14 (2000)

19. Sitzzmann, T.: A Meta-analytic Examination of the instructional effectiveness of computer-based simulation games. Personnel Psychology 64, 489-528 (2011)

20. Vorderer, P., Klimmt, C., Ritterfeld, U.: Enjoyment: At the heart of media entertainment. Communication Theory 14, 388-408 (2004)

21. Wiezer, N., Schelvis, R., van Zwieten, M., Kraan, K., van der Klauw, M., Houtman, I., Bakhuys Roozeboom, M., Kwantes, J.: Werkdruk. TNO, Hoofddorp (2012) 